\title{
Potent anti-inflammatory and antinociceptive activity of the endothelin receptor antagonist bosentan in monoarthritic mice
}

\author{
Anne-Katja Imhof', Laura Glück', Mieczyslaw Gajda², Rolf Bräuer², Hans-Georg Schaible ${ }^{3}$ and Stefan Schulz ${ }^{\text {1* }}$
}

\begin{abstract}
Introduction: Endothelins are involved in tissue inflammation, pain, edema and cell migration. Our genome-wide microarray analysis revealed that endothelin-1 (ET-1) and endothelin-2 (ET-2) showed a marked up-regulation in dorsal root ganglia during the acute phase of arthritis. We therefore examined the effects of endothelin receptor antagonists on the development of arthritis and inflammatory pain in monoarthritic mice.

Methods: Gene expression was examined in lumbar dorsal root ganglia two days after induction of antigeninduced arthritis (AIA) using mRNA microarray analysis. Effects of drug treatment were determined by repeated assessment of joint swelling, pain-related behavior, and histopathological manifestations during AIA.

Results: Daily oral administration of the mixed $\mathrm{ET}_{\mathrm{A}}$ and $\mathrm{ET}_{\mathrm{B}}$ endothelin receptor antagonist bosentan significantly attenuated knee joint swelling and inflammation to an extent that was comparable to dexamethasone. In addition, bosentan reduced inflammatory mechanical hyperalgesia. Chronic bosentan administration also inhibited joint swelling and protected against inflammation and joint destruction during AlA flare-up reactions. In contrast, the $\mathrm{ET}_{\mathrm{A}}$-selective antagonist ambrisentan failed to promote any detectable antiinflammatory or antinociceptive activity.

Conclusions: Thus, the present study reveals a pivotal role for the endothelin system in the development of arthritis and arthritic pain. We show that endothelin receptor antagonists can effectively control inflammation, pain and joint destruction during the course of arthritis. Our findings suggest that the antiinflammatory and antinociceptive effects of bosentan are predominantly mediated via the $\mathrm{ET}_{\mathrm{B}}$ receptor.
\end{abstract}

\section{Introduction}

Rheumatoid arthritis (RA) is a systemic disorder of unknown etiology and is characterized by chronic inflammation and proliferation of the synovial membrane, angiogenesis, and dysregulation of immune responses, which lead to progressive destruction of arthritic joints. A major symptom of RA is chronic recurrent pain, which results from the activation and sensitization of primary afferent nociceptors [1]. After sensitization, nociceptive neurons respond more strongly to mechanical or thermal stimulation. This process is triggered by a number of inflammatory mediators, only some of which (including IL-6, tumor necrosis factor-alpha, bradykinins, and prostaglandins) have been studied in detail [1].

\footnotetext{
* Correspondence: Stefan.Schulz@mti.uni-jena.de

'Institute of Pharmacology and Toxicology, University Hospital, Friedrich

Schiller University, Drackendorfer Str. 1, 07747 Jena, Germany

Full list of author information is available at the end of the article
}

Antigen-induced arthritis (AIA) is a well-established model of experimental arthritis in rodents and shows many similarities to human RA [2,3]. Whereas granulocyte infiltration and edema formation occur during the acute phase of AIA, the chronic phase is characterized by synovitis with infiltration of mononuclear cells into the synovial tissue, angiogenesis, pannus formation, and cartilage and bone erosion. In addition, flare-up reactions can be triggered in a timely manner in this model. We have examined gene expression changes in dorsal root ganglia (DRGs) during the acute phase of AIA. This approach led to the identification of a large number of AIA-regulated genes. Among the genes, which showed a marked upregulation, were several members of the endothelin system, including ET-1, ET-2, and $\mathrm{ET}_{\mathrm{A}}$.

The endothelin system consists of three peptide ligands (ET-1, ET-2, and ET-3), which bind to two distinct G protein-coupled receptors designated $\mathrm{ET}_{\mathrm{A}}$ and $\mathrm{ET}_{\mathrm{B}}$ [4].

\section{C) Biomed Central}


Whereas ET-1 and ET-2 can bind to $\mathrm{ET}_{\mathrm{A}}$ and $\mathrm{ET}_{\mathrm{B}}, \mathrm{ET}-3$ selectively activates $\mathrm{ET}_{\mathrm{B}}$ receptors [4]. $\mathrm{ET}_{\mathrm{A}}$ receptors have been found on small-diameter DRG neurons $[5,6]$. Activation of these neurons by ET-1 elicits increased excitability by a rise in intracellular $\mathrm{Ca}^{2+}$ and activation of voltage-gated $\mathrm{Na}^{+}$channels [7]. $\mathrm{ET}_{\mathrm{B}}$ receptors are expressed mainly in DRG satellite cells and Schwann cells [5]. It is thought that $\mathrm{ET}_{\mathrm{B}}$ receptors on these cells can stimulate prostaglandin $\mathrm{E}_{2}$ synthesis and release $[8,9]$. This study was designed to test our hypothesis that the endothelin system could represent a potential target for therapeutic intervention in RA. We therefore examined the effects of endothelin receptor antagonists on the inflammation and inflammatory pain during the course of murine antigen-induced arthritis.

\section{Materials and methods Animals}

Experiments were performed on 86 adult female C57BL/6J mice (age range of 12 to 16 weeks and body weight of 20 to $30 \mathrm{~g}$ ). Animals were housed in a climate-controlled room on a 12-hour light/dark cycle with water and standard rodent chow available ad libitum. Ethical approval was obtained before the experiments. All experiments were approved by the Thuringian state authorities and complied with European Community regulations (86/609/ EEC) for the care and use of laboratory animals.

\section{Antigen-induced arthritis}

Animals were immunized by subcutaneous injection of $100 \mu \mathrm{g}$ of methylated BSA (mBSA) (Sigma-Aldrich, Seelze, Germany) dissolved in $50 \mu \mathrm{L}$ of phosphate-buffered saline (PBS) and emulsified in $50 \mu \mathrm{L}$ of complete Freund's adjuvant (CFA) (Sigma-Aldrich) 21 and 14 days before induction of AIA. CFA was supplemented with $2 \mathrm{mg} / \mathrm{mL}$ heat-killed Mycobacterium tuberculosis strain H37RA (Difco, Heidelberg, Germany). In parallel to immunizations, $5 \times 10^{8}$ heat-inactivated Bordetella pertussis germs (Chiron-Behring, Marburg, Germany) were administered intraperitoneally. On day 0 , mice were briefly anesthetized with $2.5 \%$ isoflurane, and arthritis was induced by injecting $100 \mu \mathrm{g}$ of sterile mBSA dissolved in $20 \mu \mathrm{L}$ of PBS into the right knee joint cavity, leading to the development of severe acute synovitis associated with subsequent cartilage and bone erosion in the arthritic joint. Flare-up reactions were provoked by injecting $100 \mu \mathrm{g}$ of mBSA dissolved in $20 \mu \mathrm{L}$ of PBS on days 21 and 35 of AIA into the right knee joint cavity.

\section{mRNA microarray analysis}

For microarray analysis, mice in the AIA group $(n=3)$ were immunized with mBSA and AIA was induced in the right knee joint. Mice in the control group $(n=3)$ were immunized with mBSA but received an injection of saline into the right knee joint. On day 2 of AIA, mice were killed by cervical dislocation, and lumbar DRGs $\left(\mathrm{L}_{3}-\mathrm{L}_{5}\right.$; ipsi- and contralateral) were dissected and immediately frozen in liquid nitrogen. Successful induction of AIA was verified by measurement of joint swelling and histopathological examination. Total RNA was extracted by using RNeasy (Qiagen, Hilden, Germany) and hybridized onto an Illumina MouseWG-6 version 1.1 Expression BeadChip (Illumina, Inc., San Diego, CA, USA) at SIRSLab (Jena, Germany). Fold change of expression was defined as (AIA left - control left)/(AIA right - control right), which includes a normalization to controls. All bead types with a $P$ value of less than 0.01 and fold change of at least 5.0 and not more than -5.0 were selected for further examination by using Ingenuity Pathways Analysis Software (Ingenuity Systems, Inc., Redwood City, CA, USA). Microarray data have been deposited in a public database [10].

\section{Treatment protocol and drugs}

Drug treatment was similar to that reported in previous studies $[11,12]$. Briefly, mice were allocated to the following groups of 10 animals each under randomized conditions: $0.9 \%$ saline per os (p.o.), bosentan $100 \mathrm{mg} / \mathrm{kg}$ p.o., and ambrisentan $10 \mathrm{mg} / \mathrm{kg}$ p.o. Bosentan and ambrisen$\tan$ were dissolved in saline and administered orally in a volume of $10 \mathrm{~mL} / \mathrm{kg}$ body weight. Bosentan (RO470203) was obtained from Actelion (Basel, Switzerland). Ambrisentan (LU208075) was provided by Gilead Sciences (Foster City, CA, USA). Treatment started 2 hours before induction of AIA and was continued every 24 hours for the indicated time periods $(3,21$, or 42 days). An additional group received $0.6 \mathrm{mg} / \mathrm{kg}$ dexamethasone palmitate (Merckle, Ulm, Germany) by intraperitoneal injection. Dexamethasone treatment was carried out for 5 days followed by a 2-day pause starting 12 hours before AIA.

\section{Pain-related behavior and clinical inflammation measurement}

At two time points before AIA induction (baseline) and on days $1,3,7,14$, and 21 of AIA, secondary mechanical hyperalgesia was determined on ipsi- and contralateral hindpaws by using a dynamic plantar aesthesiometer (Ugo Basile, Comerio, Italy). Animals were placed on a mesh floor and allowed to acclimate to the testing device. Then an automated blunt filament was directed to the plantar surface of the paw, and pressure was increased until the animal withdraws its limb. The weight force needed to elicit this response was read out in grams. In this study, $10 \mathrm{~g}$ were defined as cutoff. Measurements were performed in triplicate, and means were taken as mechanical hyperalgesic thresholds. Secondary thermal hyperalgesia was assessed at hindpaws with an algesiometer (Ugo Basile) as 
described [2,13]. After acclimation of the animals to the testing device, three consecutive radiant heat stimuli were applied to the hindpaws with intervals of at least 1 minute between stimuli. Mean latencies were calculated and used as a measure of withdrawal threshold to heat. Stimuli were applied for a maximum of 10 seconds to prevent tissue damage. Swelling was assessed on days 0 to $5,7,14$, and 21 of AIA by measuring the mediolateral diameter of each knee by means of an Oditest caliper (Kroeplin, Schlüchtern, Germany). For each animal and test day, swelling was calculated by subtracting the diameter of the noninflamed knee from that of the inflamed knee to account for anatomical knee joint differences between animals.

\section{Histopathological grading of joint inflammation and destruction}

Tissues were obtained immediately after the final testing. Both knee joints were removed, skinned, fixed in $4 \%$ formalin, decalcified with $15 \%$ EDTA (ethylenediaminetetraacetic acid) for 5 days or in $7 \% \mathrm{AlCl}_{3}$ in $2.1 \% \mathrm{HCl}$ and $6 \%$ formic acid for 48 hours, embedded in paraffin, cut into $3-\mu \mathrm{m}$ thick frontal sections, and stained with hematoxylin-eosin for microscopic examination. Four sections from different levels of the knee joint were examined by an independent observer who was blinded to the treatments and were evaluated according to a histological scoring system ranging from 0 to $3(0=$ no, $1=$ mild, $2=$ moderate, and 3 = severe alterations). The amount of fibrin exudation and the relative number and density of granulocytes in synovial membrane and joint space allowed grading of the acute inflammatory reaction, and the relative number and density of infiltrating mononuclear leukocytes in the synovial membrane, the degree of synovial hyperplasia, and the extent of infiltration and fibrosis in the periarticular structures allowed grading of chronic inflammation. The extent of damage of the cartilage surface and bone structures was also evaluated on a scale of 0 to 3 , where $0=$ no damage, $1=$ mild destruction, 2 = moderate destruction, and 3 = severe destruction of cartilage and bone (extensive area of chondrocyte death and cartilage destruction and deep invasive bone erosions) [14].

\section{Statistical analyses}

For statistical analyses, SPSS for Windows (version 17.0; SPSS Inc., Chicago, IL, USA) was used. First, data were tested for normal distribution by applying the Kolmogorov-Smirnov test. Differences in histopathological scores for acute inflammation, chronic inflammation, and joint destruction as well as joint swelling were analyzed by one-way analyses of variance (ANOVAs) followed by post hoc $t$ tests for comparison between different groups. Measures obtained from different time points were compared between groups by using repeated measures ANOVAs with the between-subjects factor 'group' (vehicle, bosentan, and ambrisentan) and the within-subjects factor 'time' (baseline and days 1, 3, 7, 14, and 21 after induction of AIA). Post hoc $t$ tests were used to describe differences between groups at different time points when ANOVAs revealed a significant main effect. Significance was accepted for $P$ values of less than 0.05 . $P$ values from post hoc tests are displayed in Figures 1, 2, 3 whenever multivariate tests show significant overall effects.

\section{Results}

Effects of endothelin receptor antagonists on antigeninduced arthritis

We have assessed gene expression changes in lumbar DRGs during the acute phase of AIA by using transcriptional profiling by genome-wide microarray analysis. Intriguingly, three members of the endothelin system - namely ET-1, ET-2, and $\mathrm{ET}_{\mathrm{A}}$ - were also strongly upregulated (Table 1 ). $\mathrm{ET}_{\mathrm{B}}$ was also detected during array analysis but was not regulated (Table 1). The upregulation of ET-1 and ET-2 was then verified by real-time polymerase chain reaction (data not shown). We therefore evaluated effects of the mixed $\mathrm{ET}_{\mathrm{A}}$ and $\mathrm{ET}_{\mathrm{B}}$ endothelin receptor antagonist bosentan and the $\mathrm{ET}_{\mathrm{A}}$-selective antagonist ambrisentan on AIA in mice. Mice received daily oral administrations for 21 days beginning 2 hours before induction of AIA. Knee joint swelling and pain-related behavior were assessed repeatedly during the course of AIA (Figure 1a). On days 1 to 5 , untreated mice with AIA exhibited pronounced swelling of the injected knee, which slowly subsided until day 21 (Figure 1b). Bosentan strongly inhibited joint swelling during the acute phase of AIA (Figure 1b). In contrast, ambrisentan failed to promote any detectable anti-inflammatory effect (Figure 1b). Under these conditions, the anti-inflammatory activity of bosentan was similar to that observed after administration of dexamethasone (Figure 1c). Untreated mice with AIA also exhibited secondary thermal hyperalgesia, which was detected as decreased withdrawal latency to radiant heat (Figure 1d). Neither bosentan nor ambrisentan significantly increased latencies until paw withdrawal at the inflamed side (Figure 1d). In contrast, repeated application of dexamethasone produced a detectable inhibition of thermal hyperalgesia (Figures 1e). Untreated mice with AIA also exhibited secondary mechanical hyperalgesia, which was detected as decreased withdrawal threshold to mechanical stimuli (Figure 1f). Like mice treated with dexamethasone, bosentan-treated mice showed significantly increased mechanical thresholds at the inflamed side (Figure 1f,1g). These findings indicate that the mixed $\mathrm{ET}_{\mathrm{A}}$ and $\mathrm{ET}_{\mathrm{B}}$ endothelin receptor antagonist bosentan elicits robust anti-inflammatory and antinociceptive responses in monoarthritic mice, whereas the $\mathrm{ET}_{\mathrm{A}}$-selective antagonist ambrisentan failed to promote 


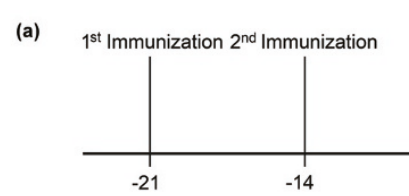

Bosentan

$100 \mathrm{mg} / \mathrm{kg} \mathrm{p.o}$

Induction of AIA Ambrisentan $10 \mathrm{mg} / \mathrm{kg}$ p.o.

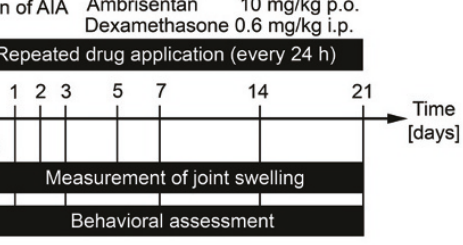

(b)
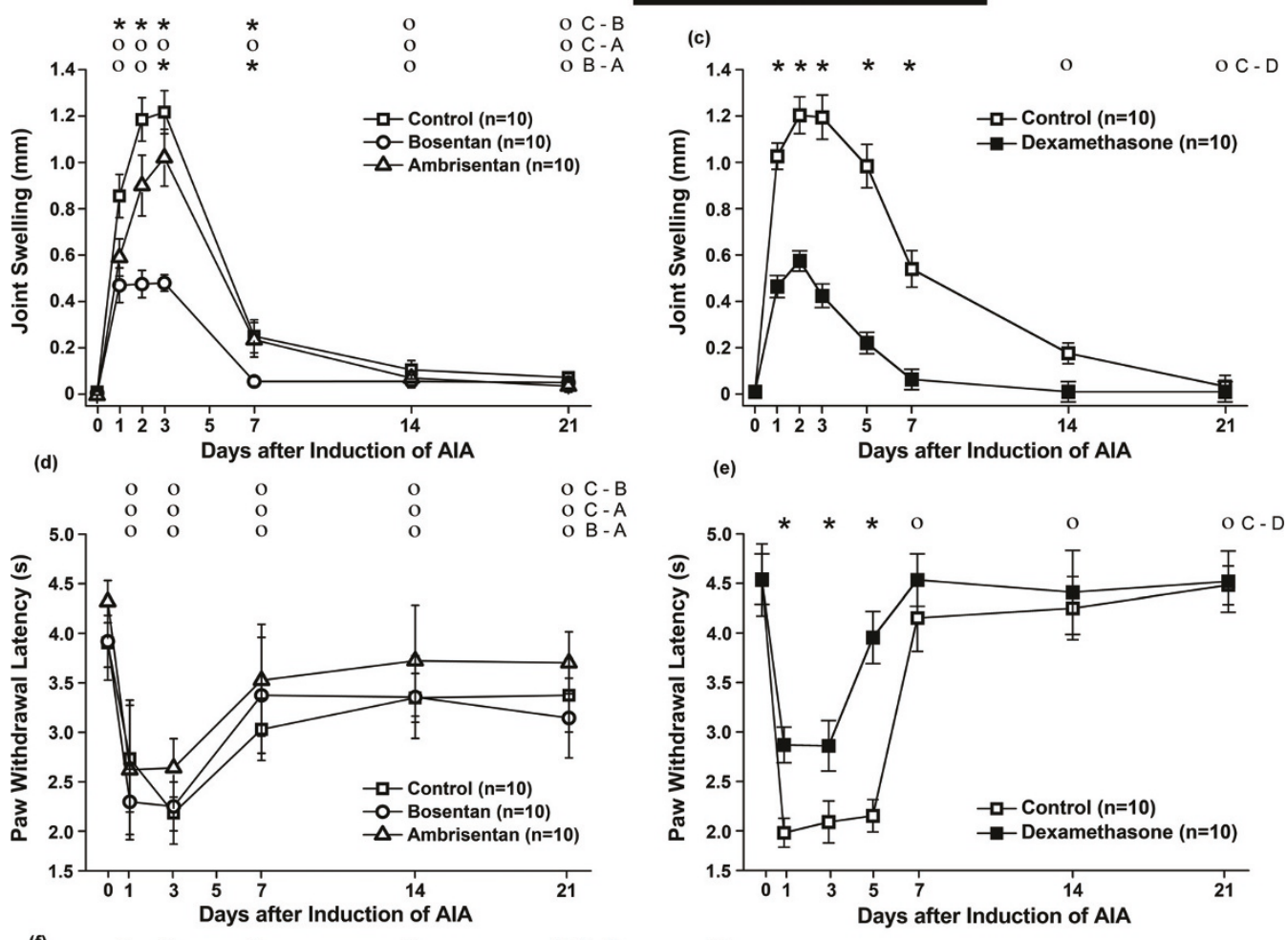

(e)
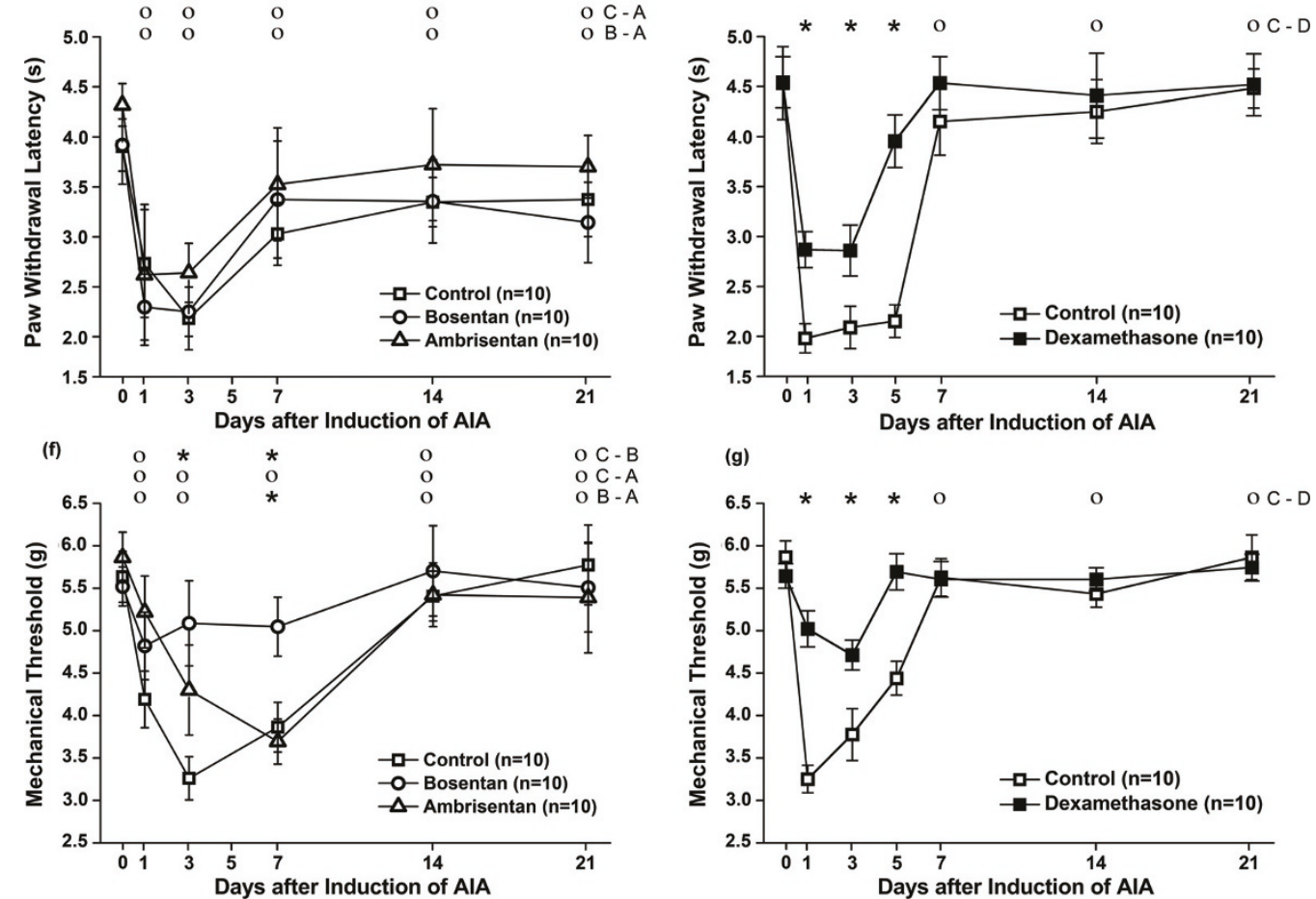

Figure 1 Effects of bosentan and ambrisentan on antigen-induced arthritis (AIA). (a) Schematic drawing of experimental setup. Animals were immunized 21 and 14 days before induction of AlA. Mice received repeated oral applications of $100 \mathrm{mg} / \mathrm{kg}$ bosentan, $10 \mathrm{mg} / \mathrm{kg}$ ambrisentan, or saline (Control) every 24 hours beginning 2 hours before induction of AIA. Dexamethasone was given intraperitoneally (i.p.) at a dose of $0.6 \mathrm{mg} / \mathrm{kg}$ for 5 days beginning 12 hours before induction of AIA. Joint swelling and pain-related behavior were assessed as indicated. All animals were tested twice during the immunization procedure to obtain baseline values depicted as day 0. (b) Inhibition of knee joint swelling by bosentan but not by ambrisentan. Knee joint swelling as an indicator of inflammation was assessed by measuring the mediolateral diameter of each knee. (c) Inhibition of knee joint swelling by dexamethasone. (d) Lack of inhibition of thermal hyperalgesia by bosentan or ambrisentan. Thermal hyperalgesia was determined with an algesiometer and calculated as reduced withdrawal threshold to heat. (e) Inhibition of thermal hyperalgesia by dexamethasone. (f) Inhibition of mechanical hyperalgesia by bosentan but not by ambrisentan. Mechanical hyperalgesia was determined on ipsi- and contralateral hindpaws by using a dynamic plantar aesthesiometer. The weight force needed to elicit a response was read out in grams. (g) Inhibition of mechanical hyperalgesia by dexamethasone. Values in (b-e) are means \pm standard error of the mean. The results from two-way analysis of variance followed by the Bonferroni post hoc test are shown ( ${ }^{*} P<0.05 ; 0$, not significant). p.o., per os (by mouth). 


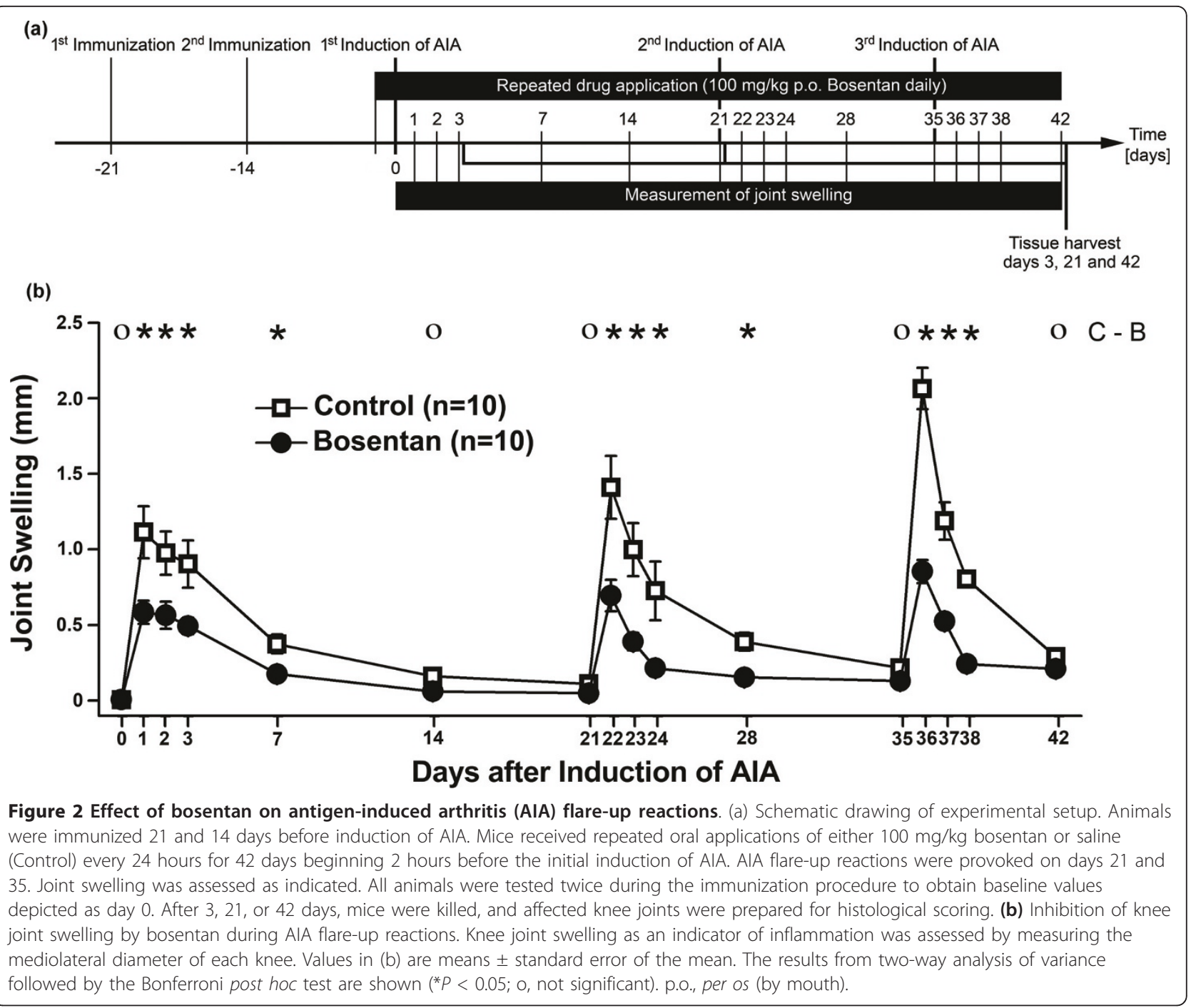

any detectable anti-inflammatory or antinociceptive activity.

\section{Effect of bosentan on antigen-induced arthritis flare-up reactions}

Given the potent anti-inflammatory and antinociceptive activity of bosentan during a single induction of AIA, we asked whether bosentan could protect against repeated induction of AIA. Mice received oral administration of bosentan every 24 hours for 42 days beginning 2 hours before the initial induction of AIA. AIA flare-up reactions were provoked 21 and 35 days later by injection of mBSA into the knee joint cavity. Knee joint swelling was assessed repeatedly during the course of AIA (Figure 2a). As depicted in Figure 2b, untreated mice responded with a pronounced increase in joint swelling during each AIA flare-up reaction. Bosentan significantly inhibited joint swelling during each of these flare- up reactions (Figure $2 \mathrm{~b}$ ). Weight loss or any other easily detectable unwanted drug effects were not noted during the 42-day treatment period. As shown in Figure 3, bosentan also potently suppressed histopathological manifestations of acute and chronic inflammation detected 3 days after AIA induction as well as inflammation and joint destruction during AIA flare-up reactions.

\section{Discussion}

In an effort to examine gene expression changes during experimental arthritis, we found that three members of the endothelin system - namely ET-1, ET-2, and $\mathrm{ET}_{\mathrm{A}}$ were markedly upregulated during the acute phase of AIA. This is in line with previous findings showing that patients with RA exhibit increased ET-1 serum levels as well as high ET-1 concentrations in synovial fluid [15-17]. Moreover, it is widely accepted that endothelins 


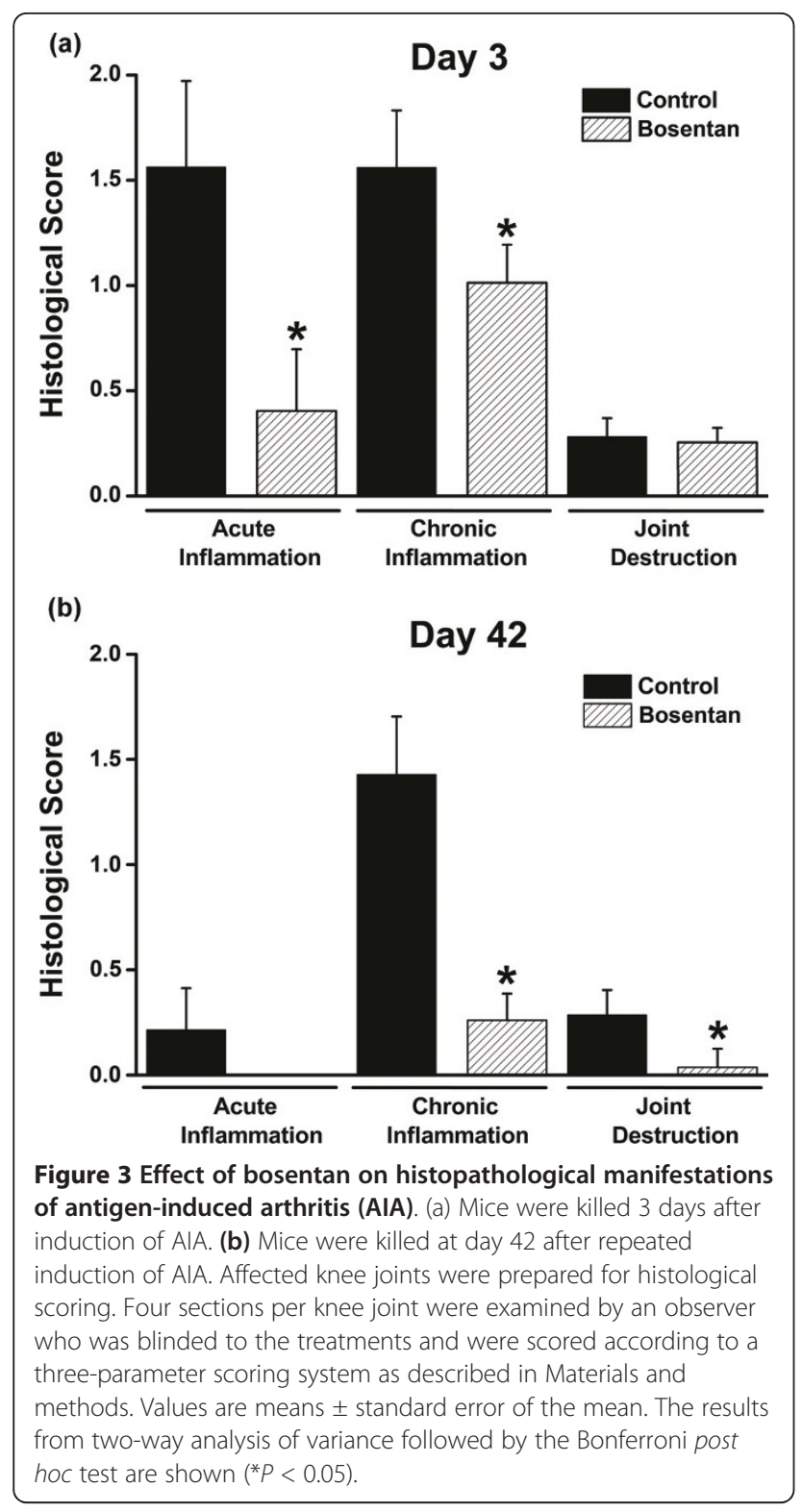

induce hypernociception in rodents [18-22]. So far, studies investigating the role of endothelins in the pathophysiology of arthritis are sparse [18,23,24]. It has been shown, however, that local administration of endothelin receptor antagonists reduces edema, neutrophil infiltration, and production of inflammatory mediators [21,25-32].

Given the availability of potent endothelin receptor antagonists, we investigated the effects of systemic administration of the mixed $\mathrm{ET}_{\mathrm{A}}$ and $\mathrm{ET}_{\mathrm{B}}$ endothelin receptor antagonist bosentan and the $\mathrm{ET}_{\mathrm{A}}$-selective antagonist ambrisentan on pain-related behavior, inflammation, and histopathological manifestations during the course of AIA. We found that daily oral administration of bosentan significantly attenuated knee joint swelling.
In contrast, ambrisentan failed to promote any detectable anti-inflammatory activity. These findings indicate that the anti-inflammatory effects of bosentan are mediated predominantly via the $\mathrm{ET}_{\mathrm{B}}$ receptor.

Bosentan selectively inhibited mechanical hyperalgesia but not thermal hyperalgesia. Acute and chronic models of joint inflammation reliably produce mechanical hyperalgesia. In some arthritic models, thermal hyperalgesia can also be observed; however, it is not known to what extent thermal hyperalgesia is important in humans. Interestingly, intradermal injection of ET-1 induces mechanical hyperalgesia in humans, whereas thermal hyperalgesia could not be observed. Moreover, previous findings revealed different contributions of $\mathrm{ET}_{\mathrm{A}}$ and $\mathrm{ET}_{\mathrm{B}}$ receptors to thermal and mechanical hyperalgesia, respectively $[2,9,21,25,28,29,31-34]$. Whereas $\mathrm{ET}_{\mathrm{A}}$ receptors have been shown to mediate ET-1-induced thermal hyperalgesia, $\mathrm{ET}_{\mathrm{B}}$ receptors have been linked to mechanical hyperalgesia [2,9,21,25,28,29,31-34]. Both ambrisentan and bosentan had no effect on thermal hyperalgesia. In contrast, dexamethasone produced a significant inhibition of thermal hyperalgesia, suggesting that mechanisms in addition to an upregulation of ET-1 or ET-2 may contribute to the development of thermal hyperalgesia in our AIA model. At present, we do not know whether $\mathrm{ET}_{\mathrm{B}}$-selective antagonists could exert therapeutic effects similar to those of mixed $\mathrm{ET}_{\mathrm{A}}$ and $\mathrm{ET}_{\mathrm{B}}$ receptor antagonists. Nevertheless, daily oral bosen$\tan$ administration was well tolerated over the 42-day treatment period in our murine AIA model.

To assess gene expression changes in lumbar DRGs during the acute phase of AIA, we used transcriptional profiling by genome-wide microarray analysis. Our results indicate that an acute peripheral inflammation of the knee joint induces robust changes in gene expression patterns in DRGs, suggesting that dynamic adaptations occur in primary sensory neurons in response to peripheral inflammation. However, this approach is based on the isolation of total mRNA from DRGs and, hence, cannot differentiate between mRNAs originating from neurons, glial cells, endothelial cells, or infiltrating leukocytes. Nevertheless, we detected a total of 451 AIA-regulated genes, 436 of which were upregulated (fold change of at least 5) and only 15 of which were downregulated (fold change of not more than -5) in DRGs from the affected side in comparison with the contralateral side and control animals. Table 1 shows a selection of upregulated genes. This selection includes regulatory peptides (for example, secretin, peptide YY, and guanylin) as well as chemokines, receptors, enzymes, and carriers. Several of these genes, including phospholipase A2, kallikrein, IL-18, and CX3CL1, have been associated with arthritis or inflammatory pain. 
Table 1 Selected genes that are upregulated in dorsal root ganglia two days after induction of antigen-induced arthritis as determined by microarray analysis

\begin{tabular}{|c|c|c|c|}
\hline Illumina ID & Gene & Synonym & Fold change \\
\hline scl0011829.2_75-S & $A Q P 4^{\mathrm{a}}$ & Aquaporin 4 & 9 \\
\hline scl27591.6.1_80-S & $A R E G^{a}$ & Amphiregulin & 10 \\
\hline scl27547.3.1_4-S & BMP3 & Bone morphogenetic protein 3 & 8 \\
\hline scl26388.10_270-S & BTC & Betacellulin & 5 \\
\hline scl026365.2_7-S & CEACAM1 & Carcinoembryonic antigen-related cell adhesion molecule & 13 \\
\hline scl0023844.2_19-S & CLCA3 & $\mathrm{Ca}^{2+}$-activated chloride channel & 1,724 \\
\hline scl020312.5_187-S & $\mathrm{CX} 3 \mathrm{CL}^{\mathrm{a}}$ & Chemokine (C-X3-C motif) ligand 1 & 6 \\
\hline scl48937.1.1_21-S & $C X A D R$ & Coxackie and adenovirus receptor & 15 \\
\hline scl31983.48.1_26-S & $D M B T 1$ & Deleted in malignant brain tumors & 678 \\
\hline scl44852.5.1_6-S & $E D N 1^{\mathrm{a}}$ & Endothelin 1 & 16 \\
\hline scl25019.5.1_161-S & EDN2 & Endothelin 2 & 5 \\
\hline scl15480.1.1_277-S & $E D N R A^{\mathrm{a}}$ & Endothelin receptor A & 7 \\
\hline scl45193.8_18-S & $E D N R B$ & Endothelin receptor B & 1 \\
\hline scl0001767.1_56-S & FAM3B & Family with sequence similarity 3 , member $B$ & 10 \\
\hline scl43662.2_474-S & F2RLI & F2RL1 coagulation factor II receptor-like 1 & 28 \\
\hline scl48150.3.1_29-S & FAM3D & Family with sequence similarity 3 , member $\mathrm{D}$ & 18 \\
\hline scl47093.2_645-S & GPR2O & G protein-coupled receptor 20 & 22 \\
\hline scl53162.3.1_182-S & GPR120 & G protein-coupled receptor 120 & 6 \\
\hline scl0232431.4_71-S & GPRC5A & G protein-coupled receptor, family C, group 5, member A & 62 \\
\hline scl25025.4.1_56-S & GUCA2A & Guanylin & 802 \\
\hline scl016173.8_28-S & $1 L 18^{\mathrm{a}}$ & Interleukin 18 & 6 \\
\hline scl49177.8_486-S & ILDR1 & Ig-like domain-containing receptor 1 & 26 \\
\hline scl016612.5_71-S & $K L K 1^{a}$ & Kallikrein 1 & 113 \\
\hline Gl_6754459-S & $K L K 1 B 26$ & Kallikrein 1-related peptidase b26 & 112 \\
\hline scl018050.1_7-S & KLK1B4 & Kallikrein 1-related peptidase b4 & 127 \\
\hline scl000139.1_0-S & KLK1B5 & Kallikrein 1-related peptidase b5 & 302 \\
\hline scl0016619.1_79-S & $K L K 3$ & Kallikrein 1-related peptidase b27 & 121 \\
\hline scl49904.15_203-S & MEPIA & Meprin A, alpha & 20 \\
\hline sc|48741.4.1_176-S & PLA2G4F & Phospholipase A2 & 93 \\
\hline scl39519.5.1_59-S & PYY & Peptide YY & 72 \\
\hline scl16482.8_0-S & $R A B 17$ & Member of RAS oncogene family & 9 \\
\hline scl24993.3_35-S & RHBDL2 & Rhomboid, veinlet-like 2 & 5 \\
\hline scl22946.3.1_72-S & S100A14 & S100 calcium-binding protein & 55 \\
\hline scl32104.13.1_7-S & SCNNIB & Na-channel, nonvoltage-gated 1, beta-subunit & 7 \\
\hline scl30493.4.19_120-S & $S C T^{\mathrm{a}}$ & Secretin & 9 \\
\hline scl20135.8.1_22-S & SDCBP2 & Syndecan-binding protein (syntenin) 2 & 41 \\
\hline scl026456.19_173-S & SEMA4G & Semaphorin $4 G$ & 9 \\
\hline scl0020510.2_224-S & SLCIA1 & Solute carrier family 1 , member 1 & 5 \\
\hline scl32784.15.1_26-S & SLC7A9 & Solute carrier family 7 , member 9 & 11 \\
\hline scl00226999.1_58-S & SLC9A2 & Solute carrier family 9, member 2 & 31 \\
\hline scl00171286.2_214-S & $S L C 12 A 8$ & Solute carrier family 12, member 8 & 16 \\
\hline scl39885.12.1_61-S & SLC13A2 & Solute carrier family 13, member 2 & 47 \\
\hline scl47037.12.1_89-S & SLC39A4 & Solute carrier family 39, member 4 & 16 \\
\hline scl41202.6.1_16-S & $S L C 46 A 1^{a}$ & Solute carrier family 46, member 1 & 5 \\
\hline
\end{tabular}

Genes were annotated by using Illumina (San Diego, CA, USA) and National Center for Biotechnology Information databases. ${ }^{\mathrm{a}}$ Genes previously associated with arthritis or inflammatory pain.

\section{Conclusions}

We identify the endothelin system as a potential target for therapeutic intervention in RA by mRNA microarray analysis. We clearly show that chronic oral bosentan administration inhibits joint swelling, protects against joint inflammation and destruction, and reduces mechanical hyperalgesia during AIA induction and during AIA flare-up reactions. Thus, our findings on the endothelin system provide proof of concept that global gene expression profiling can 
lead to the identification of novel therapeutic targets in arthritis.

\begin{abstract}
Abbreviations
AIA: antigen-induced arthritis; ANOVA: analysis of variance; CFA: complete Freund's adjuvant; DRG: dorsal root ganglion; ET-1: endothelin-1; ET-2: endothelin-2; $E T_{A}$ : endothelin receptor $A_{;} E T_{B}$ : endothelin receptor $B ;$ interleukin; mBSA: methylated bovine serum albumin; PBS: phosphatebuffered saline; p.o: per os (by mouth); RA: rheumatoid arthritis.
\end{abstract}

\section{Acknowledgements}

We thank Heike Stadler (Institute of Pharmacology) and Cornelia Hüttich and Renate Stöckigt (Institute of Pathology) for excellent technical assistance, Marc Iglarz from Actelion for providing bosentan, and Irmela Mai de Cortez from Gilead Sciences for providing ambrisentan. This study did not receive any public or private funding.

\section{Author details}

'Institute of Pharmacology and Toxicology, University Hospital, Friedrich Schiller University, Drackendorfer Str. 1, 07747 Jena, Germany. ${ }^{2}$ Institute of Pathology, University Hospital, Friedrich Schiller University, Ziegelmühlenweg 107743 Jena, Germany. Institute of Physiology I, University Hospital, Friedrich Schiller University, Teichgraben 8, 07743 Jena, Germany.

\section{Authors' contributions}

A-KI carried out the experiments and drafted the manuscript. LG carried out the experiments and helped to draft the manuscript. MG carried out the histopathological examination. RB and H-GS participated in the design of the study and helped to draft the manuscript. SS conceived the study, participated in its design and coordination, and helped to draft the manuscript. All authors read and approved the final manuscript.

\section{Competing interests}

The authors declare that they have no competing interests.

Received: 5 October 2010 Revised: 13 April 2011

Accepted: 20 June 2011 Published: 20 June 2011

\section{References}

1. Schaible HG, Richter F, Ebersberger A, Boettger MK, Vanegas H, Natura G, Vazquez E, Segond von Banchet G: Joint pain. Exp Brain Res 2009, 196:153-162.

2. Boettger MK, Hensellek S, Richter F, Gajda M, Stockigt R, von Banchet GS, Brauer R, Schaible HG: Antinociceptive effects of tumor necrosis factor alpha neutralization in a rat model of antigen-induced arthritis: evidence of a neuronal target. Arthritis Rheum 2008, 58:2368-2378.

3. Brackertz D, Mitchell GF, Mackay IR: Antigen-induced arthritis in mice. I. Induction of arthritis in various strains of mice. Arthritis Rheum 1977, 20:841-850.

4. Masaki T: Historical review: endothelin. Trends Pharmacol Sci 2004, 25:219-224.

5. Pomonis JD, Rogers SD, Peters CM, Ghilardi JR, Mantyh PW: Expression and localization of endothelin receptors: implications for the involvement of peripheral glia in nociception. J Neurosci 2001, 21:999-1006.

6. Stosser S, Agarwal N, Tappe-Theodor A, Yanagisawa M, Kuner R: Dissecting the functional significance of endothelin $A$ receptors in peripheral nociceptors in vivo via conditional gene deletion. Pain 2010, 148:206-214.

7. Zhou Z, Davar G, Strichartz G: Endothelin-1 (ET-1) selectively enhances the activation gating of slowly inactivating tetrodotoxin-resistant sodium currents in rat sensory neurons: a mechanism for the paininducing actions of ET-1. J Neurosci 2002, 22:6325-6330.

8. Khodorova A, Montmayeur JP, Strichartz G: Endothelin receptors and pain. J Pain 2009, 10:4-28.

9. Khodorova A, Zou S, Ren K, Dubner R, Davar G, Strichartz G: Dual roles for endothelin- $B$ receptors in modulating adjuvant-induced inflammatory hyperalgesia in rats. Open Pain J 2009, 2:30-40.

10. [ftp://Imhof_et_al._2011:Wai2goha@ftp.sirs-lab.com/].
11. Bien S, Riad A, Ritter CA, Gratz M, Olshausen F, Westermann D, Grube M, Krieg T, Ciecholewski S, Felix SB, Staudt A, Schultheiss HP, Ewert R, Volker U, Tschope C, Kroemer HK: The endothelin receptor blocker bosentan inhibits doxorubicin-induced cardiomyopathy. Cancer Res 2007, 67:10428-10435.

12. Shaw SG, Boden JP, Biecker E, Reichen J, Rothen B: Endothelin antagonism prevents diabetic retinopathy in NOD mice: a potential role of the angiogenic factor adrenomedullin. Exp Biol Med (Maywood) 2006, 231:1101-1105.

13. Boettger MK, Weber K, Schmidt M, Gajda M, Brauer R, Schaible HG: Gait abnormalities differentially indicate pain or structural joint damage in monoarticular antigen-induced arthritis. Pain 2009, 145:142-150.

14. Gruen M, Rose C, Konig C, Gajda M, Wetzker R, Brauer R: Loss of phosphoinositide 3-kinase gamma decreases migration and activation of phagocytes but not T cell activation in antigen-induced arthritis. BMC Musculoskelet Disord 2010, 11:63.

15. Haq A, El-Ramahi K, Al-Dalaan A, Al-Sedairy ST: Serum and synovial fluid concentrations of endothelin-1 in patients with rheumatoid arthritis. $J$ Med 1999, 30:51-60.

16. Pache M, Schwarz HA, Kaiser HJ, Wuest P, Kloti M, Dubler B, Flammer J: Elevated plasma endothelin-1 levels and vascular dysregulation in patients with rheumatoid arthritis. Med Sci Monit 2002, 8:CR616-619.

17. Yoshida H, Imafuku Y, Ohhara M, Miyata M, Kasukawa R, Ohsumi K, Horiuchi J: Endothelin-1 production by human synoviocytes. Ann Clin Biochem 1998, 35:290-294.

18. Conte Fde P, Barja-Fidalgo C, Verri WA Jr, Cunha FQ, Rae GA, Penido C, Henriques MG: Endothelins modulate inflammatory reaction in zymosaninduced arthritis: participation of LTB4, TNF-alpha, and CXCL-1. J LeukoC Biol 2008, 84:652-660.

19. Hamamoto DT, Khasabov SG, Cain DM, Simone DA: Tumor-evoked sensitization of C nociceptors: a role for endothelin. J Neurophysiol 2008, 100:2300-2311.

20. Klass M, Hord A, Wilcox M, Denson D, Csete M: A role for endothelin in neuropathic pain after chronic constriction injury of the sciatic nerve. Anesth Analg 2005, 101:1757-1762.

21. Motta EM, Chichorro JG, Rae GA: Role of ET(A) and ET(B) endothelin receptors on endothelin-1-induced potentiation of nociceptive and thermal hyperalgesic responses evoked by capsaicin in rats. Neurosci Lett 2009, 457:146-150

22. Namer B, Hilliges M, Orstavik K, Schmidt R, Weidner C, Torebjork E, Handwerker $\mathrm{H}$, Schmelz M: Endothelin 1 activates and sensitizes human C-nociceptors. Pain 2008, 137:41-49.

23. Daher JB, Souza GE, D'Orleans-Juste P, Rae GA: Endothelin ETB receptors inhibit articular nociception and priming induced by carrageenan in the rat knee-joint. Eur J Pharmacol 2004, 496:77-85.

24. Verri WA Jr, Guerrero AT, Fukada SY, Valerio DA, Cunha TM, Xu D, Ferreira SH, Liew FY, Cunha FQ: IL-33 mediates antigen-induced cutaneous and articular hypernociception in mice. Proc Natl Acad Sci USA 2008, 105:2723-2728.

25. Chichorro GJ, Zampronio RA, Rae AG: Endothelin ET(B) receptor antagonist reduces mechanical allodynia in rats with trigeminal neuropathic pain. Exp Biol Med (Maywood) 2006, 231:1136-1140.

26. Griswold DE, Douglas SA, Martin LD, Davis TG, Davis L, Ao Z, Luttmann MA, Pullen M, Nambi P, Hay DW, Ohlstein EH: Endothelin B receptor modulates inflammatory pain and cutaneous inflammation. $\mathrm{Mol}$ Pharmacol 1999, 56:807-812.

27. Khodorova A, Navarro B, Jouaville LS, Murphy JE, Rice FL, Mazurkiewicz JE, Long-Woodward D, Stoffel M, Strichartz GR, Yukhananov R, Davar G: Endothelin- $B$ receptor activation triggers an endogenous analgesic cascade at sites of peripheral injury. Nat Med 2003, 9:1055-1061.

28. Motta EM, Chichorro JG, D'Orleans-Juste P, Rae GA: Roles of endothelin ETA and ETB receptors in nociception and chemical, thermal and mechanical hyperalgesia induced by endothelin- 1 in the rat hindpaw. Peptides 2009, 30:918-925.

29. Piovezan AP, D'Orleans-Juste P, Souza GE, Rae GA: Endothelin-1-induced $\mathrm{ET}(\mathrm{A})$ receptor-mediated nociception, hyperalgesia and oedema in the mouse hind-paw: modulation by simultaneous $\mathrm{ET}(\mathrm{B})$ receptor activation. Br J Pharmacol 2000, 129:961-968.

30. Verri WA, Molina RO, Schivo IR, Cunha TM, Parada CA, Poole S, Ferreira SH, Cunha FQ: Nociceptive effect of subcutaneously injected interleukin-12 is 
mediated by endothelin (ET) acting on ETB receptors in rats. $J$ Pharmacol Exp Ther 2005, 315:609-615.

31. Verri WA Jr, Schivo IR, Cunha TM, Liew FY, Ferreira SH, Cunha FQ: Interleukin-18 induces mechanical hypernociception in rats via endothelin acting on ETB receptors in a morphine-sensitive manner. J Pharmacol Exp Ther 2004, 310:710-717.

32. Yuyama H, Koakutsu A, Fujiyasu N, Fujimori A, Sato S, Shibasaki K, Tanaka S, Sudoh K, Sasamata M, Miyata K: Inhibitory effects of a selective endothelin-A receptor antagonist YM598 on endothelin-1-induced potentiation of nociception in formalin-induced and prostate cancerinduced pain models in mice. J Cardiovasc Pharmacol 2004, 44(Suppl 1): S479-482.

33. Menendez L, Lastra A, Hidalgo A, Baamonde A: Nociceptive reaction and thermal hyperalgesia induced by local ET-1 in mice: a behavioral and Fos study. Naunyn Schmiedebergs Arch Pharmacol 2003, 367:28-34.

34. Verri WA Jr, Cunha TM, Magro DA, Guerrero AT, Vieira SM, Carregaro V, Souza GR, Henriques MG, Ferreira SH, Cunha FQ: Targeting endothelin ETA and ETB receptors inhibits antigen-induced neutrophil migration and mechanical hypernociception in mice. Naunyn Schmiedebergs Arch Pharmacol 2009, 379:271-279.

doi:10.1186/ar3372

Cite this article as: Imhof et al:: Potent anti-inflammatory and

antinociceptive activity of the endothelin receptor antagonist bosentan in monoarthritic mice. Arthritis Research \& Therapy 2011 13:R97.

\section{Submit your next manuscript to BioMed Central} and take full advantage of:

- Convenient online submission

- Thorough peer review

- No space constraints or color figure charges

- Immediate publication on acceptance

- Inclusion in PubMed, CAS, Scopus and Google Scholar

- Research which is freely available for redistribution

Submit your manuscript at www.biomedcentral.com/submit 